and for routine tests on fruits and vegotables and their products. As a whole, much is included that is of interest to those who are concerned with quality control in food production; the symposium fully discussed the difficulties in correlating colour and quality -in particular, the necessity for considering separately each commodity in terms of its natural colour and of the changes during storage and processing, and also in terms of what is regarded as acceptable and desirable by the consumer. In this connexion, the symposium brings out not only differences in individual and community preferences, but also the effects of external factors such as modern restaurant lighting.

\section{Archæological and Geological Investigations in}

\section{South Australia}

Australian investigators continue to advance our knowledge of the prehistory of their regions. Long ago it was suggested that little further progress could be mado until sites yielding a definite stratigraphy of industries had been discovered and a correlation of cultures with the geological record determined; and further, that in this connexion the fauna associated with the various culture groups must be listed. The problems there are not at all easy to resolve. Prehistory continued until a recent date, and neither the later geology nor the palæontology has been as systematically studied as in Western Europe. A recent number of the Records of the South Australian Museum (11, No. 3; 1955) is a useful addition to our knowledge. It contains a long article on the late Tertiary marsupials of South Australia and continues with a study of certain archæological sites at Lake Menindee, a locality near the River Darling in western New South Wales. The Lake is almost always dry except in exceptionally wet periods, such as that, for example, of 1950. In the dune-like area noar the northern end of the Lake a stratigraphical sequence of several cultures has been determined, namely, the Tartangan (at the base) and then the Pirrian, with the Mudukian on top. The remains of a fauna and some human bones have been recovored. The industries are made from material foreign to the district, and it would appear that we are dealing with hunting peoples who from time to time occupied the sites either when it was damp or during times of exceptionally heavy rainfall when the Lake had water in it. $Y_{t}$ would seem clear that at Menindee man was contemporary with extinct marsupials which he hunted for food, and that the dingo only arrived in New South Wales after the time of the first settlement. The age of the earliest levels could be the close of the Pleistocene or the very beginning of the Holocene. The account is well set out; but the illustrations are not adequate in the case of the stone implements. The drawing of stone tools is a specialized art, and more attention could well have been paid to it.

\section{Scientific Research in India}

IN his Thomas Holland Memorial Lecture, given before the Royal Society of Arts on May 19, Sir Alfred Egerton spoke on "Scientific Research in India". After emphasizing that the fruitfulness of science is first and foremost not a matter of money but of outstanding men or women, Sir Alfred said that although much was started before India attained independence, including the Board of Scientific and Industrial Research and, later, the Council of Scientific and Industrial Research to administer the Industrial
Rescarch Fund, scientific research only obtained full recognition and encouragement after 1947. This Lecture was essentially an account of the national research laboratories and institutes of India, the work of which was reviewed by a committee with Sir Alfred Egerton as chairman. Sir Alfred thought that the creation of this chain of laboratories in so short a time and the organization it has involved are fine achievements which provide young Indian scientists with the means to show their mettle. He has faith in India's young scientists and technologists and believes that, with initiative and integrity, patience and persistence, they will do work in these institutes which will make them a worthy memorial to India's great public servant, the late Sir Shanti Bhatnagar.

Scientific Research at South African Universities

A THIRD volume of the "Register of Current Scientific Research at South African Universities" has now been issued, covering research carried out in 1954 (pp. 262. Pretoria : Library and Information Division, Council for Scientific and Industrial Research, 1954). The entries are alranged alphabetically by university departments under their English names; but subject and description are given in the language in which the information was received: in future, it is proposed to supply an English translation of the subject where that is submitted in Afrikans. There is no indox; but a list of contents and a few cross-references afford reasonable safeguards against any particular research being overlooked, and even a comprehensive index could scarcely eliminate the need for a careful examination of the entries in any broad field.

\section{Plant List of North-West Europe}

UNDER the editorship of the Lund Botanical Society, comprehensive lists are being prepared of the plants of north-west Europe, including those of Swoden, Norway, Denmark, East Fennoscandia, Iceland and the Faeroes. In these lists, all species are given point values indicating their rareness within the area of the list, and their occurrence in the different countries is indicated by 'country signs'. Introduced species of diverse kinds are distinguished from the native ones by different types. The main list is completed by lists of synonyms (those most widely used are also given in the main list), of plants protected by law and registers. The present volume on vascular plants has been prepared by Nils.Hylander (15 Swedish kroner). A similar list of mosses, algae and lichens (by $H$. Weimarck, T. Levring and $H$. Magnusson, respectively) was issued in 1936-37.

\section{Audio-Frequency Power Measurements}

THe eighth in the series of "Notes on Applied Science" propared by the National Physical Laboratory, Teddington, is a brief pamphlet dealing with "Audio-Frequency Power Measurements" (pp. 16. London: H.M.S.O., 1954; 1s. net). The concept of electrical power and its measurement is introduced by a theoretical consideration of a simple twoterminal load carrying a d.c. current and having negligible leakage between it and its surroundings; and the basic principles of power measurements in an a.c. system free of coupling are outlined before describing in detail the theory of operation of the three modern types of wattmeter. It is stated that on theoretical grounds the electrodynamic type of instrument is the least suitable for the higher audio. 